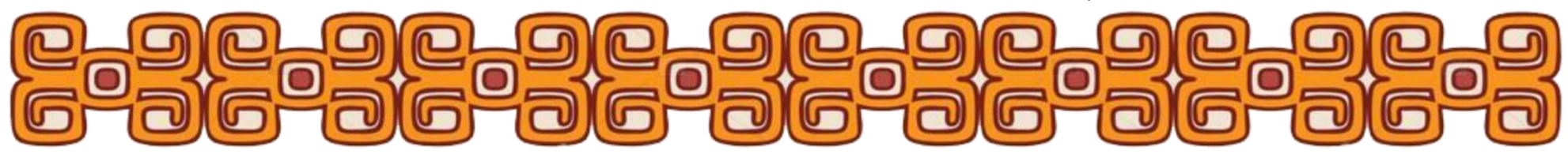

\title{
A PRODUÇÃO ECONÔMICA SUSTENTÁVEL EM UNIDADE DE CONSERVAÇÃO: UMA ANÁLISE SOBRE O PARQUE NACIONAL DO VIRUÁ QUANTO ÀS PRÁTICAS CIVILIZATÓRIAS PARA A MANUTENÇÃO DA BIODIVERSIDADE AMAZÔNICA DO PANTANAL RORAIMENSE
}

\section{RESUMO}

Shigeaki Ueki Alves da Paixão Gláucio Campos Gomes de Matos

O artigo tem base no trabalho de campo, e se apropria do viés eliasiano para a análise, cujo. O objetivo é destacar as configurações para a compreensão da interação homem - natureza diante dos modelos de gestão sustentável com vistas ao aprimoramento da utilização das Unidades de Conservação para a consolidação do turismo de base comunitária, da Unidade de Conservação Parque Nacional do Viruá no Estado de Roraima. Este é um importante patrimônio natural, da faixa de transição e a manutenção da lógica de proteção dos ecossistemas e biodiversidade. Incorporado ao contexto, e inserindo-se nessa percepção e interpretação de configurações e redes de interdependências funcionais em que se firmam como principais alternativas para os avanços em geração de renda e justiça social, bem como a sua comprovação como mecanismo indutor do crescimento do índice de desenvolvimento humano em sintonia, equilíbrio e respeito à natureza, reduzindo os impactos negativos e enfrentamento à degradação, biopirataria, que tanto assola o espaço em função das ações antrópicas na floresta amazônica.

\section{PALAVRAS CHAVES}

Unidade de Conservação; Figurações; Turismo Ecológico; Sustentabilidade ; Cultura; Amazônia.

\section{INTRODUÇÃO}

O ordenamento do espaço onde a concentração significativa do ambiente natural em que a biodiversidade do lugar representa diretamente a manutenção do equilíbrio ecológico e, sobretudo, das condições da qualidade de vida da humanidade, traduzem-se como indutoras ao processo qualitativo em que a produção econômica sustentável deve basear seus estudos. Isso exige dos envolvidos o entendimento da interdependência,

"[...] cada pessoa singular está realmente presa; está por viver em permanente dependência funcional de outras; ela é um elo nas cadeias que ligam outras pessoas, assim como todas as demais, direta ou indiretamente, são elos nas cadeias que as prendem. Essas cadeias não são visíveis e tangíveis, como grilhões de ferro. São mais elásticas, mais variáveis, mais mutáveis, porém não menos reais, e decerto não menos fortes. E é a essa rede de funções que as pessoas desempenham umas em relação a outras, a ela e a nada mais, que chamamos "sociedade"'". (ELIAS, 1994, p. 21). \section{\{}




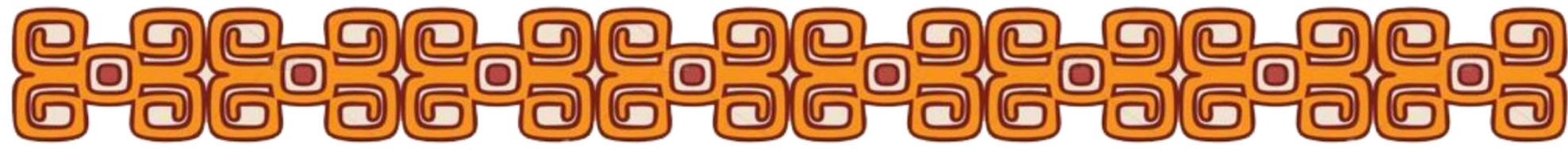

Verifica-se nesse limiar a importância de estabelecermos a constante sinergia integradora, capaz de promover a interações necessárias para que os seres inseridos nesse contexto possam manter-se continuamente interligados ao melhor processo de estruturação e ordenamento do espaço, a fim de que sejam concebidas relações mútuas e significativas ao manejo e desenvolvimento sustentável no ecossistema, garantindo para todos a sua relevância ao implemento dos vários processos de produção sustentável entre a sociedade e a natureza.

Registramos que na década de 90, segundo Val (1991) os pensamentos e análises apontam para a racionalidade em ocupações na Amazônia, como observaremos em Val.

\footnotetext{
"A ocupação da Amazônia sempre foi pautada em modelos desenvolvimentistas (Moran, 1982), ignorando-se os voltados para a preservação ou pela combinação de ambos. Apenas na década de 80 é que se intensificaram os movimentos preservacionistas na região, mas os resultados negativos causados pela ocupação desenvolvimentista persistem e tendem a agravar a situação em diversas partes da Amazônia. [...] Torna-se imprescindível desenvolver modelos de ocupação racional da região para que haja condições de autossustentação da população e preservação desta flora e fauna tão diversificada. Qualquer modelo sério visando uma ocupação racional da Amazônia precisa levar em conta pelo menos, os seguintes tópicos: meios de preservação da flora e fauna regional; colonização planejada e bem distribuída a autossustentação e uso adequado da terra". (VAL, 1991, p.47)
}

Assim, tem-se já demarcada bases de diálogos que norteiam a utilização gerencial eficaz, prevendo toda a relevância do manejo para o desenvolvimento de práticas sustentável como mecanismo vetorial da qualidade das reconfigurações a serem pensadas para o bioma Amazônico.

Esse é o sentido das interdependências funcionais, pois requer o envolvimento de muitos agentes nesse processo de articulação e as configurações existentes no espaço natural em prol do bem comum, verificando-se o reconhecimento de sua existência histórica de vivenciam e detentores da mais genuína responsabilidade de proteção dos ecossistemas, provenientes das suas experiências registradas no decorrer do período de sua interação com o Parque Nacional do Viruá. Nesse sentido,

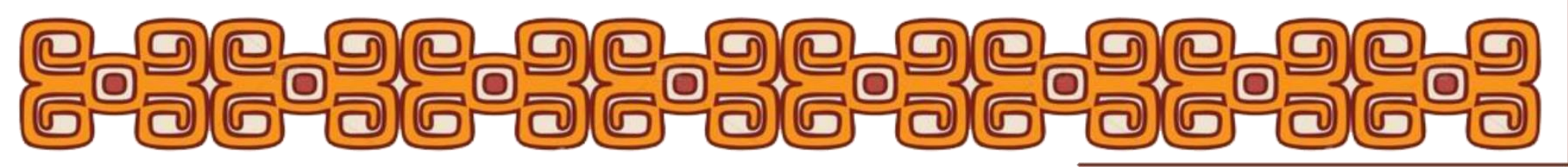




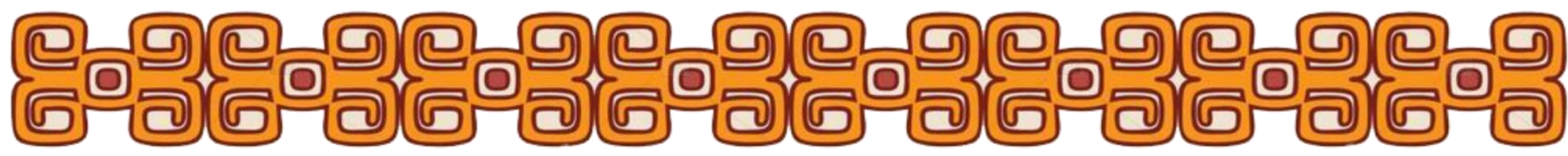

"[...] são as figurações, por assim dizer, a orientarem os humanos para o capitalismo, socialismo; para as ações ecológicas ou para o comportamento religioso; para a subsistência, sustentabilidade ou predação a ponto de minar espécies do ambiente e dificultar a permanência do indivíduo no espaço onde estabeleceu sua morada. Nessas figurações, o nível de tensão ocorrendo, momentâneas, outras mais elásticas, pode diferir entre indivíduos, entre grupos, mas também entre indivíduos e grupos de outras figurações. Isso quer dizer que quem extrai madeira ilegal vai em oposição àqueles que têm o dever de protegê-la". (MATOS, 2015, p.19).

Desse modo, as divisões devem ser condizentes as responsabilidades e compromissos que cada indivíduo exercerá durante a confirmação de sua presença, demarcadas na territorialidade do lugar; buscando-se o compromisso com os órgãos de fiscalização e conservação desse ambiente tão complexo ambiente, pois, a natureza não está isolada como também o ser humano em sua essência não se manterão inertes as dinâmicas do lugar, seja para sobreviver ou mesmo na relação da sua própria existência, como é pontuado por Norbert Elias: "[...] quanto mais essa divisão avança numa sociedade e maior é o intercambio entre as pessoas, mais estreitamente elas são ligadas pelo fato de cada uma só poder sustentar sua vida e sua existência social em conjunto com muitas outras" (ELIAS, 1994, p. 44).

\section{AS CONFIGURAÇÕES NO CONTEXTO DO PARQUE NACIONAL DO VIRUÁ EM RORAIMA}

O Parque Nacional do Viruá guarda a história do período em que era utilizado por ribeirinhos para o extrativismo da sorva, para a pesca e exploração de produtos da fauna, procurados pelo mercado regional desde meados do século XIX.

"A relação de interdependência funcional entre seres humanos, em pleno século $X X I$, pode até ser vagamente compreendida ou incompreendida por conta da direção do processo de individualização em curso. No entanto, no período da borracha, nos confins do Amazonas, ou melhor, nos centros da mata e margens de rios, essa relação por parte dos seringueiros era mais do que necessária e muito bem

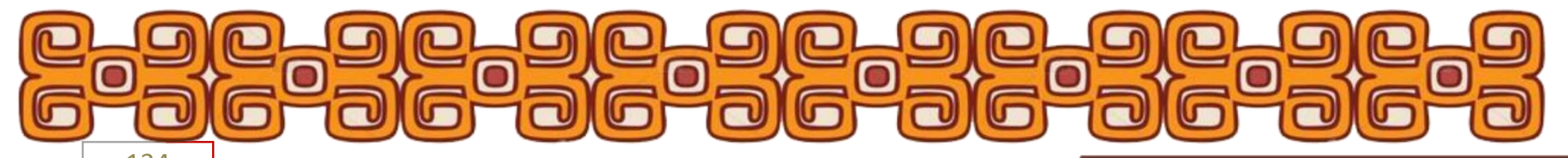




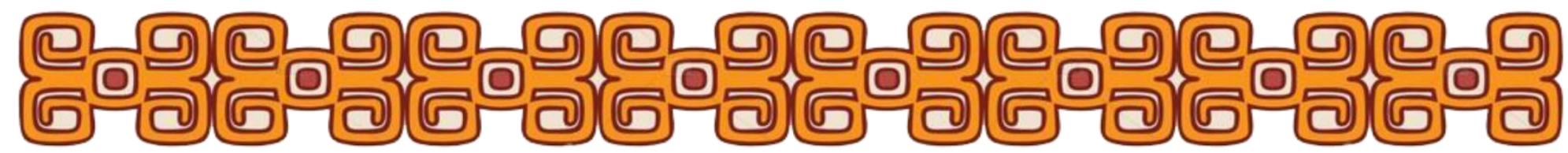

Ao tomar como referência a visão historicista de manejo dos recursos naturais, é possível afirmar que o estabelecimento da relação homem-natureza é determinada, em grande medida, pelo contexto sócio-histórico e a gestão dos recursos naturais pelas populações tradicionais, em uma lógica não capitalista, garante a (re) produção dos recursos em uma perspectiva de sustentabilidade. (RODRIGUES, 2015, p. 30)

Há nesse sentido o profundo conjunto de sistemas simbólicos e manifestações socioculturais, necessários para incorporação no conjunto de elementos imagéticos e culturais, bem como associados ao patrimônio natural vinculado a memória tanto do espaço do Parque Nacional do Viruá quanto da demografia de seus moradores históricos, que constituem esse universo repleto de registros históricos, produção sociocultural e a constante relação com os sistemas comunicacionais do ecossistema.

\begin{abstract}
"A extração da sorva encerrou-se na região na década de 1980, e muitos dos que viviam desta função habitam hoje a sede municipal de Caracaraí. Sua história requer ainda uma investigação sistemática e profunda, pois constitui uma das mais relevantes memórias da formação do povo deste Município e de sua estreita relação com o patrimônio natural da região. Parte importante da memória dos antigos moradores e pescadores do rio Iruá, especialmente no que se refere às terminologias utilizadas para a designação de paisagens e ambientes". (BRASIL, 2014, P.5-1).
\end{abstract}

Tais registros históricos contribuem para a formulação de muitos roteiros turísticos, históricos e ecológicos no universo de todo o ambiente da dinâmica territorial do lugar, no qual são repletos de novas possibilidades, em que a organização de modelos de gestão para a promoção de receptivos constituem-se em ferramentas de inclusão das gerações que vivem no Parque Nacional do Viruá em Roraima, tornando-se atrações a memória do lugar por meio de reproduções de réplicas das instalações de onde eram realizadas as atividades extrativistas e mesmo pelo percurso do rio, que em sua nova adensamento podem ser realizados distintas práticas do perímetro do rio.

"Nas últimas décadas, a Região Norte tem sido o palco de grandes mudanças na sua dinâmica demográfica, impulsionadas pelas políticas governamentais iniciadas no início da segunda metade do século passado. Nesse processo, novas tendências demográficas passaram a se delinear na

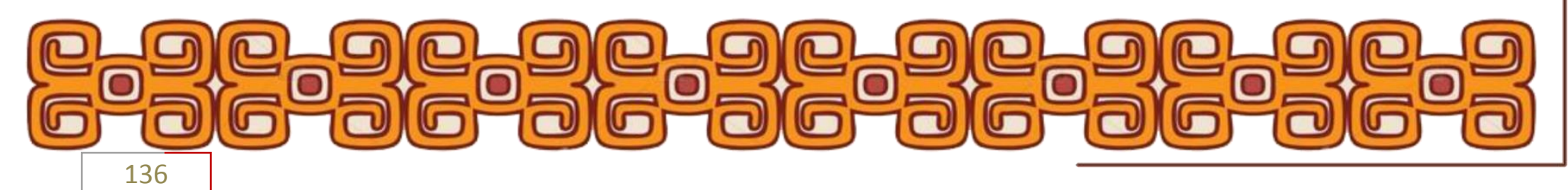




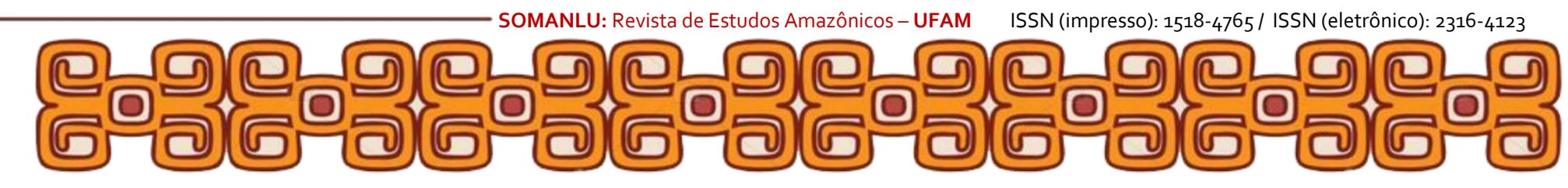

Certo é que essa terminologia é ainda muito nova e está por definir seus contornos, pois se encontra no início de sua vida (CUNHA e ALMEIDA, p. 184, 2001). Por essa razão, de maneira arbitrária, optamos pela utilização do termo "populações tradicionais" com o intuito de englobar, ainda que artificialmente, os povos indígenas, quilombolas e as comunidades locais. Reconhecemos o diferencial estabelecido pela Convenção 169 da Organização Internacional do Trabalho (OIT) de que os povos indígenas e tribais devem ser identificados como povos que possuem autodeterminação, e a adoção da presente terminologia não implica seu afastamento. Ao mesmo tempo, temos a perspectiva já assinalada por Edna Castro (2000, p. 165) que ressalta o uso da denominação "povos tradicionais" como autonomeação, expressa "elementos de identidade política e reafirmação de direitos". Doravante, a adoção do termo "populações tradicionais" será utilizada de modo a incluir nesta categoria: "não apenas as comunidades indígenas, como também outras populações que vivem em estreita relação com o ambiente natural, dependendo de seus recursos naturais para a sua reprodução sociocultural, por meio de atividades de baixo impacto ambiental" (SANTILLI, 2002, p. 90). (MOREIRA, 2007, p. 34 e 35).

Nas configurações do parque, há de se destacar, a responsabilidade de cada integrante do contexto produtivo, porque sua função se estabelece na vanguarda para avanços, assim como as principais vertentes que conduzem a um nível elevado da relação homem natureza, que diante desse contexto histórico, cultural e memória, temos o Parque Nacional do que possui estrutura abrangente para a coordenação de projetos estruturantes, em todo seu perímetro.

\section{A PANORÂMICA HISTÓRICA E MANUTENÇÃO DA BIODIVERSIDADE NO PNV-}

RR

O Parque Nacional do Viruá está inscrito sob a jurisdição do decreto de criação, do dia 29 de abril de 1998, suas referenciais geográficos dos limites constam georreferenciados a oeste o rio Branco, a nordeste o traçado da BR-174, a leste o traçado da Estrada Perdida, ao sul o rio Anauá, integra o bioma da Amazônia e corresponde a uma faixa de transição natural, caracterizando-se pela a existência de mosaicos amazônicos, sua fitofisionomias que são verificadas a existência das:

Campinaranas, Florestas Ombrófilas Densas e Abertas, Formações pioneiras.

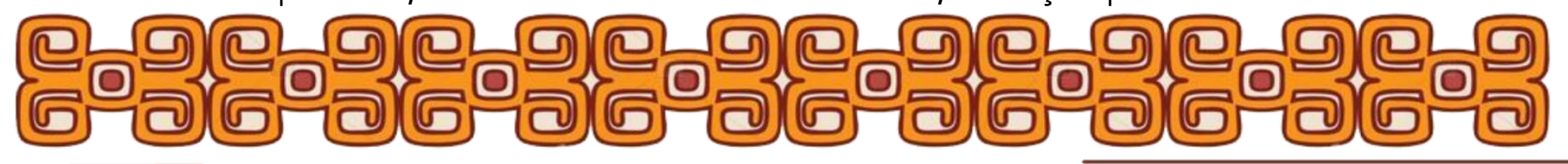




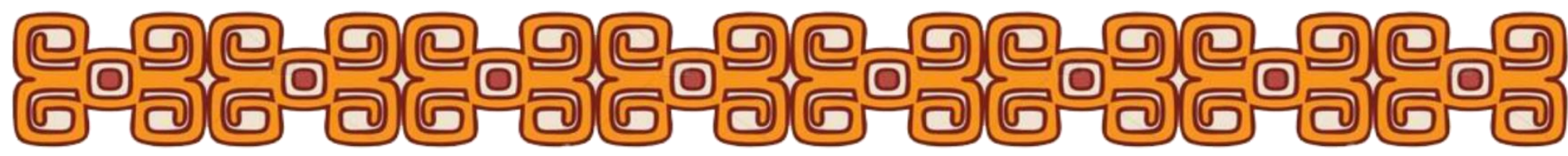

Estamos diante do exemplar modelo em defesa da Floresta Amazônica, que requer perspectivas para a sua viabilidade econômica, com vista às populações tradicionais viventes no contexto no PNV-RR como ressalta Rivas.

\begin{abstract}
"A economia tem sido descrita frequentemente como o estudo de como se fazer escolhas ou de como estudar a alocação de recursos escassos. Embora este estudo tenha sido sempre o foco da economia ambiental e dos recursos naturais, ainda é evidente que temos dificuldades em confrontar essas escolhas e decidir entre a preservação ambiental e outras atividades econômicas e sociais. Observe que para tais decisões não é necessário desistir nem da qualidade ambiental para se obter uma melhor economia nem dos benefícios econômicos para se ter melhor qualidade do bem-estar social. Muitos tomadores de decisão, no entanto, têm evitado confrontar decisões difíceis, especialmente quando a decisão envolve custos no presente e benefícios no futuro". (RIVAS, 2014, p. 35).
\end{abstract}

Nesse sentido, temos todas as favoráveis apontando para o implemento e aprimoramento das práticas sustentáveis para a melhor disposição do ambiente natural vetor para o desenvolvimento de base comunitária e integrada às pesquisas científicas. Somando-se a todo o contexto, temos a localização estratégica do Parque Nacional do Viruá é também uma excelente alternativa para a atração de turistas internacionais, pois está localizado na região centro-sul do Estado de Roraima, no Município de Caracaraí-RR, a 200 km de Boa Vista, cuja Capital indutora do turismo local é também a cidade para turistas oriundos de distintas nacionalidades interessados em conhecer o bioma amazônico, e isso viabilizaria uma nova rota do consumo por meio do Turismo Ecológico, que tem a observação de pássaros como uma de suas ferramentas de interação com o meio natural, o acesso é feito por meio da BR-174, rodovia federal que interliga o Estado do Amazonas ao Estado de Roraima, sendo porta de entrada para os turistas vindos da América Central, e os da Europa por meio das Capitais dos Países fronteiriços Caracas-Venezuela e Georgetwon-Guyana, além de manter direta relação com o Caribe.

Portanto, condições favorecem a percepção do espaço amazônico paras as práticas sustentável e rentável sem impactos negativos e predatórios aos sistemas ecológicos, mas sob o controle e vigilância tanto dos comunitários treinados, quanto

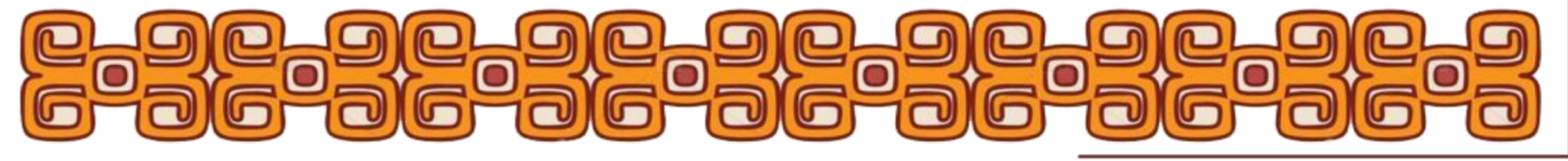




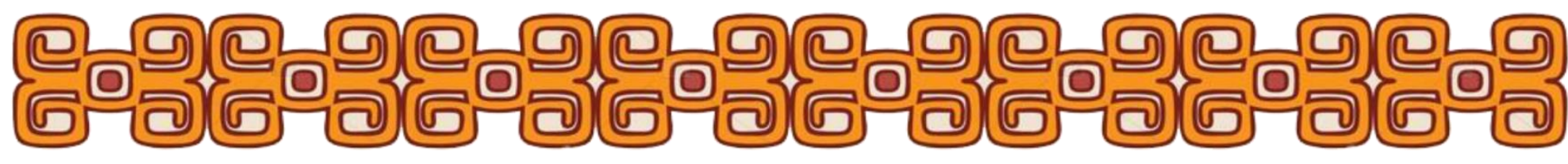

tradicionais, além de promovendo visitas guiadas para estudantes de nível

fundamental e ensino médio de escolas do entorno e região para ampliar seu caráter formador por meio de aulas de campo para alunos de graduação e pós-graduação dos mais distintos programas de pós-graduação do Brasil; cursos para comunitários, apresentações culturais. Como destaca Rivas em suas análises.

\begin{abstract}
"Os serviços ecológicos são importantes para os processos econômicos de produção. Por exemplo, refrigerantes podem ser produzidos a um custo menor caso a empresa possua uma fonte de água tratada. A produção de micro chips, a qual requer um ambiente de produção "super-limpo" é menos dispendiosa numa área ainda puro do que numa área com o ambiente repleto de partículas e outros tipos de poluições atmosféricas. Os sistemas ecológicos também contribuem indiretamente para os sistemas sociais, porque níveis elevados de serviços ecológicos proporcionam saúde para outros ecossistemas para os quais os serviços ecológicos são exportados. Como por exemplo, uma área costeira alagada fornece habitat para espécies jovens de peixes que passarão a vida adulta nos oceanos. Sem os sistemas alagados para dar suporte e proteger o desenvolvimento destes peixes jovens, os oceanos seriam menos produtivos." (RIVAS, 2014, p.39).
\end{abstract}

No Pantanal Roraimense, as aves migratórias embelezam além de as paisagens cênicas naturais e servem ao campo científico em prol da humanidade. Para sensibilizar aqueles que visitam o parque, participarão de caminhadas ecológicas, em que terão a oportunidade de realizarem a observação de aves de espécies diferentes, reunidas em um bioma único de faixa de transição na Amazônia.

Na programação da caminhada, o visitante ou pesquisador será contemplado com a observação da vida silvestre, a oportunidade da prática do ciclismo, banho, turismo e outras atividades de lazer. Tal proposta vem ser consolidada pela viabilização do Plano de Manejo do Parque Nacional do Viruá.

Como ressalta Rivas, há de se compreender que para todos os impactos, devem-se prever as análises de manejo viáveis a toda interação e integração entre serviços ofertados e a rica biodiversidade envolvida no processo.

"O serviços ecológicos promovem a estabilidade e resiliência para os ecossistemas bem como para outros ecossistemas com os quais se conecta.

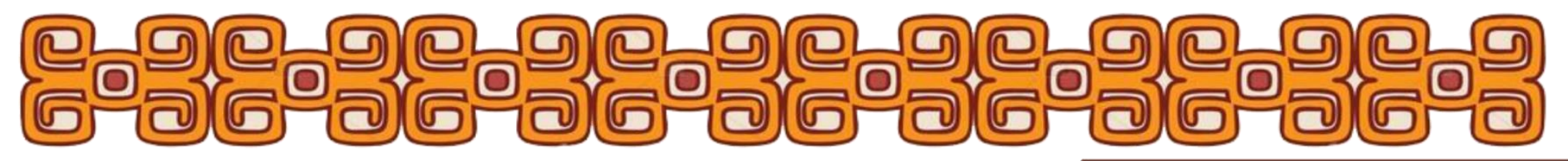




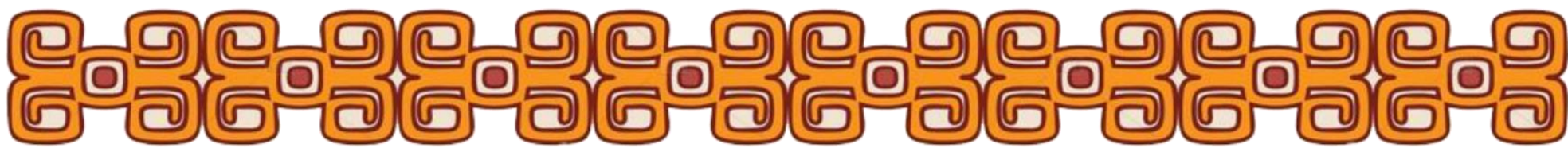

Esses serviços são denominados de serviços ecossistêmicos". (RIVAS, 2014, p. 177).

Nesse sentido, observa-se o potencial ao desenvolvimento de atividades econômicas sustentáveis em total sinergia com as adaptações previstas em termos gerenciais para o desenvolvimento de atividades de baixo impacto em Unidade de Conservação e que viabilizam a inserção humana de forma equânime e estrutura-se rumo à otimização do espaço para as gerações vindouras.

No contexto atual em que observamos as práticas predatórias assim como a exploração do trabalho análogo ao escravo, por serem oferecidas por madeiras e grandes latifundiários, que exploram a terra por meio da monocultura e uso de agrotóxicos, e somada a essa assolador avanços, temos a plantação de transgênico em lavouras, anteriormente griladas em procedimentos irregulares de terras, antes ambientes naturais repletos de biodiversidade, reproduzindo de forma desordenada o pensamento assolador ao ambiente natural amazônico.

Essa situação compromete os avanços sociais, pois não se registra a qualidade do Índice de Desenvolvimento Humano pela falta de oportunidade rentável, limpa e com vistas à justiça social, bem como, ao impacto negativo gerado em distintos biomas no território nacional brasileiro, pois mediante aos ataques a natureza temos comprometida muito da riqueza sem termos apresentações de nenhum modelo gerencial viável para a população brasileira, assim como para a comunidade científica, que precisa de garantias para a manutenção do ambiente amazônica para os estudos em ciência e tecnologia. Desafiadoras são algumas das posições nas quais teremos que ultrapassar como aponta Rivas.

\footnotetext{
"Apesar de imprescindíveis para a existência de vida no planeta, nem todos os serviços ecossistêmicos são plenamente conhecidos pelo homem. Considerando que no ambiente todos componentes estão interligados e são interdependentes, tem-se a interferências humana em determinado elemento afetará o ambiente como um todo, sendo difícil indicar com precisão todos os efeitos indiretos que determinada intervenção humana terá no ambiente. Consequentemente, há grandes entraves para a perfeita identificação dos impactos que as atuais atividades humanas causam aos serviços ecossistêmicos.
}

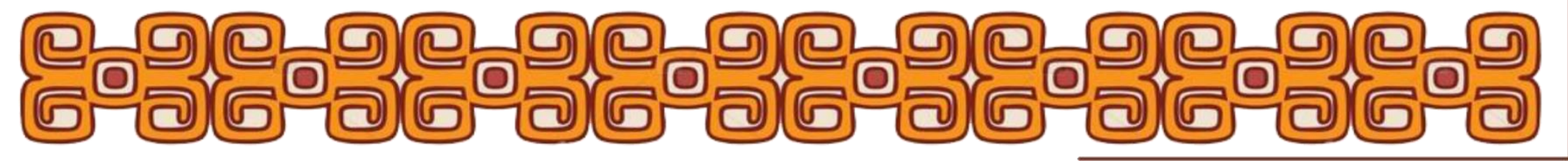




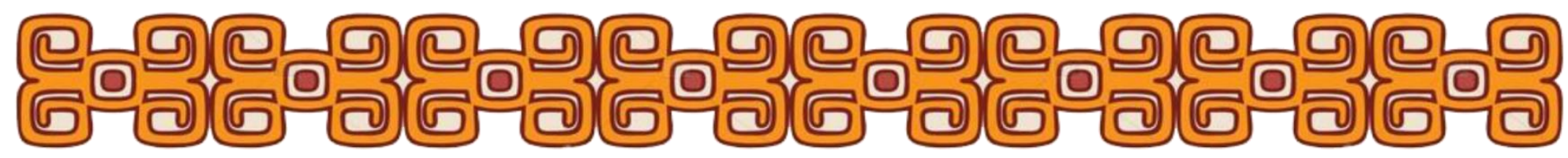

O desmatamento de uma floresta, por exemplo, implicaria em algo muito maior do que a mera perda dos recursos ambientais ali existentes (árvores, folhas, frutos, biodiversidade associada), uma vez que afetaria todo o ambiente, envolvendo a perda de diversos serviços ecossistêmicos por ela oferecidos". (RIVAS, 2014, p.177).

Assim, os estudos promovidos evidenciam condições para a sua aplicação de forma organizada e qualitativa e aceitável para a viabilização de condições das novas práticas sustentáveis a serem incorporadas, como medidas de inserção da humanidade e inclusão social das populações nela existente, para a viabilização da empregabilidade e como fonte de renda para a população: comunidades tradicionais (povos indígenas) e população ribeirinha (pescadores e extrativistas), como a prática do Turismo sustentável em área ecológica (turismo científico), contemplados no diagnóstico e planejamento do Parque Nacional do Viruá Estado de Roraima/ PNVRR, estabelecendo claras condições das diretrizes estratégicas da Unidade de Conservação - UC, bem como o zoneamento, e as normas e atividades voltadas para o alcance de objetivos sustentáveis à gestão e incorporação de ações estruturantes em prol do contexto produtivo de base comunitária e a manutenção do bioma em constante análise para a sua certificação para o desenvolvimento de produtos e serviços de origem ambientalmente adequada para a sua execução qualitativa.

\footnotetext{
"A consciência da interação entre o homem e a natureza toda relação pressupõe uma interferência equilibrada entre as partes. Os índios são defensores de que a natureza tem suas regras e limites; sua forma de interferir (caça, colheita e extrativismo) é que demonstra a noção do delicado equilíbrio dos ecossistemas". (VIANA, 2008, p.57)
}

O Zoneamento do Parque Nacional do Viruá expressa a estratégia para o desenvolvimento e manejo da visitação no PNV com base em ferramenta específica de planejamento do uso público, viabilizando experiências de gestão participativa e adaptativa na UC. Rivas ressalta a adoção da gestão e manutenção dos serviços ecossistêmicos como compromissos de primeira ordem.

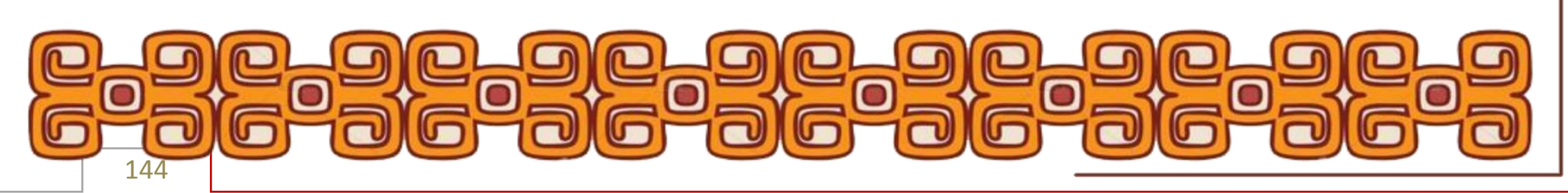




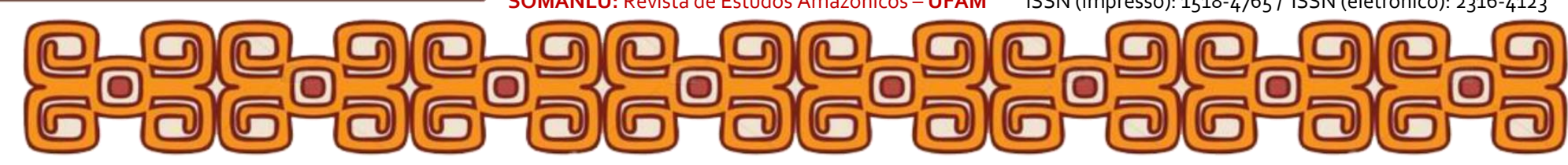

"A manutenção e a gestão de serviços ecossistêmicos constituem-se em um desafio, uma vez que se faz necessário considerar as interações espaciais e temporais entre sociedade e ecossistemas que resultam em seu provimento. Alguns serviços ecossistêmicos podem gerar benefícios em escala regional, no entanto, seus custos se manifestam somente na escola local. Poe exemplo, a água de irrigação captada por comunidades rio abaixo pode ter como consequência (custo) o rebaixamento do lençol freático na localidade rio acima, ocasionando perde de solo e da qualidade do solo. Outros podem operar no sentido contrário. Como no caso da produção de alimentos em piscicultura que poderia veneficiar comunidades locais, mas cujos efluentes, no entanto, podem provocar a polvição e outros cursos na região. Outro desfio político à gestão de serviços ecossistêmicos deriva do fato de estes operarem em escalas que cruzam fronteiras geopolíticas, ou seja, quando o provimento dos serviços ecossistêmicos e a subsequente captura de seus benefícios ocorrem em regiões distintas, separadas por grandes distâncias e localizadas em diferentes jurisdições. Os serviços ecossistêmicos dever ser compreendido dentro dessa perspectiva multidimensional e interativa do meio ambiente (interação entre os sistemas ecológicos e sociais), como mais um dos benefícios que o meio ambiente proporciona à humanidade gratuitamente". (RIVAS, 2014, p.178).

A incorporação desse modelo promove significativa a interação humana com a natureza, garantindo seu manejo, bem como provendo a sua própria autogestão por meio da entrada de recursos financeiros gerados a partir do fluxo turístico, e do envolvimento da população tradicional vivente do ambiente do parque em substituições aos modelos danosos, como a pesca predatória, e não apenas de subsistência, a biopirataria proveniente de grandes grupos interessados na pesquisa científica no território brasileiro, sem obedecer às normas vigentes, como a utilização do bioma para possível garimpagem, por estar inserida em ambiente de riqueza mineral reconhecida internacionalmente, além do extrativismo irregular no ambiente natural do parque, como as matérias de maior interesse que são as madeiras genuínas do bioma, com forte força no mercado internacional desse produto.

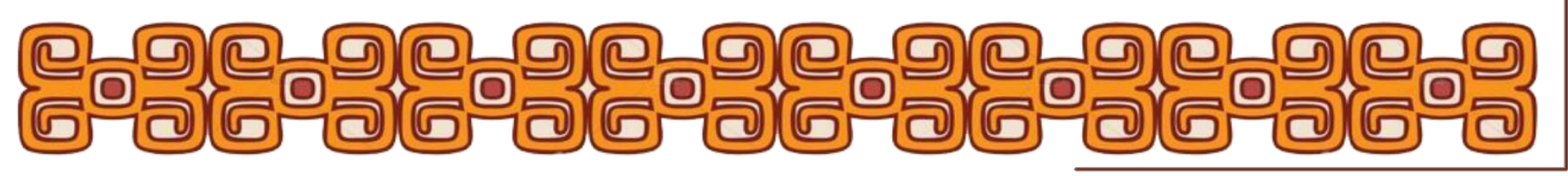




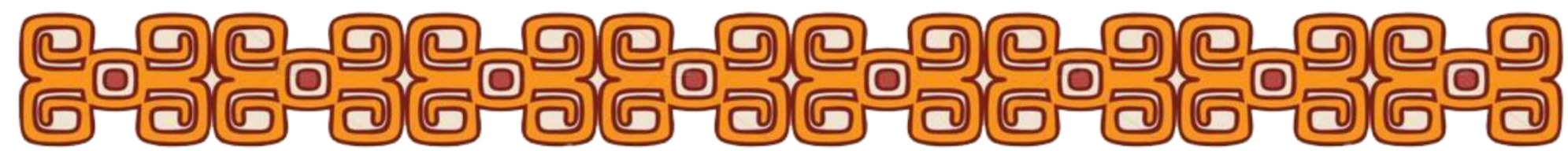

4. OS IMPACTOS PRODUTIVOS PARA O DESENVOLVIMENTO SUSTENTÁVEL NO PNV-RR

Uma contribuição para a devastação do ecossistema amazônico tem sido protagonizada, por um número representativo de moradores que adentram a Amazônia e ocupam de forma irregular determinadas porções protegidas ambientalmente, nesse sentido, viabilizar condições de acesso democrático aos recursos que beneficiem a qualidade de vida e o índice de desenvolvimento humano são procedimentos essenciais, para que os mesmos não pactuem com os modelos exploratórios, que encontram nesse subterfugio, espaços suficientes para degradar em nome da geração de emprego e renda contaminados com a voracidade e degradação dos espaços naturais.

\footnotetext{
"A aventura que é o pensamento independente altamente individualizado, a postura através da qual a pessoa prova que é uma "inteligência criativa", não tem como precondição apenas um "talento natural" individual muito particular. Ela só é possível dentro de uma estrutura específica de equilíbrios de poder; sua precondição é uma estrutura social bastante específica. E depende, além disso, do acesso que o indivíduo tem, numa sociedade assim estruturada, ao tipo de aprendizagem e ao pequeno número de funções sociais que, elas apenas, permitem desenvolver-se sua capacidade independente de reflexão". (ELIAS, 1994b, p.232).
}

A sociedade mais justa é também a mais preocupada com as suas configurações, evidenciando-se claramente os aspectos que ilustram a riquezas dessas interações para a manutenção da vida e dos ecossistemas em que estão inseridas, assim a sociedade sempre buscará encontrar mecanismos de fortalecimento dos intercâmbios, porque "ninguém dúvida de que os indivíduos formam a sociedade ou de que toda sociedade é uma sociedade de indivíduos" (ELIAS, 1994a, p. 16).

\footnotetext{
"A concepção de biodiversidade ou de diversidade biológica não pode ser entendida, única e exclusivamente do ponto de vista da biologia, em uma perspectiva isolada e sem relação com o contexto social mais amplo, mas deve ser compreendida, enquanto construção dos homens,
}

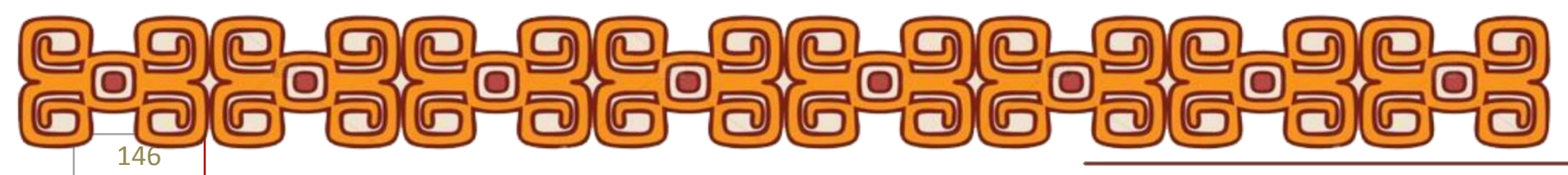




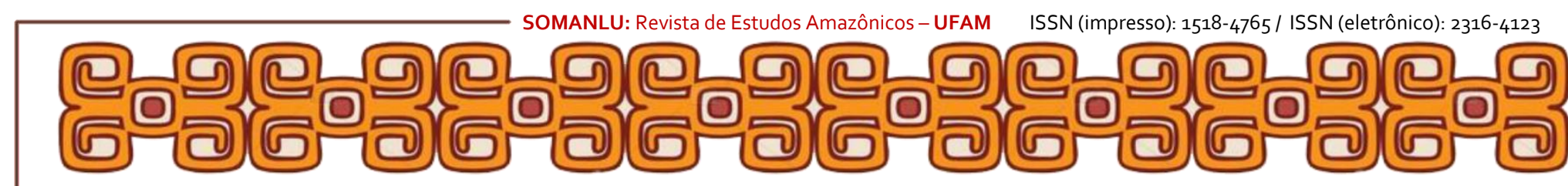

no estabelecimento de suas relações em uma perspectiva histórica e social, a partir do momento em que estes imprimem significados às coisas e ao meio onde vivem". (RODRIGUES, 2015, p. 28)

As análises apontam para a necessidade de conhecimento e interação constante entre seus agentes e o ecossistema em debate, para que sejam amplamente aprimorados de modo a contemplar ações estruturantes e vetores do crescimento humano em sintonia com a vigência que viabilizam a manutenção social, implementada por condições econômicas viáveis para o implemento de todos os processos produtivos, tanto na condição de vida humana, assim como para o aprimoramento de estudos científicos que canalizem aperfeiçoamentos e preservem a rica biodiversidade.

E tais comprometidos deverão partir individualmente de cada ser, pois a queimada criminosa ou por uso descontrolado é um exemplo simples da falta de consciência cometida por um único indivíduo, que somente é evitada mediante a formação em seu processo educacional, assim constata-se que "a capacidade humana, somente desenvolvida pela socialização, de se ver a si próprio através dos olhos alheios ou, simplesmente, de perceber e sentir o próprio ego como objeto, além de sujeito (VILA NOVA, 2009, p.133), cabendo sobremaneira à participação coletiva no Parque Nacional do Viruá para modificarmos a atuação individualiza do ser no meio ambiente.

Por outro lado, dando atenção às práticas tradicionais provindas de moradores antigos, há de levar em consideração, segundo Matos (2015), que as populações tradicionais, se apropriam da queimada para limpeza e fertilização do solo, controle da natureza, sem, contudo, terem a intenção de provocar danos ambientais.

O complexo reunido no Parque Nacional do Viruá traduz-se singularmente como uma alternativa empreendedora na ordem e na lógica de ocupação com vistas ao guarnecimento das áreas protegidas, sem com isso limitar os avanços de ações estruturantes que se somem ao implemento de políticas públicas capazes de desenvolver com eficácias questões sociais, ainda sem complementaridade como a falta de emprego nos centros urbanos, mas múltiplas as perspectivas com olhares

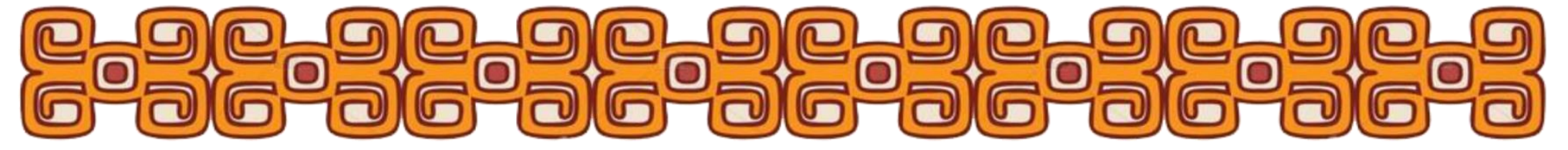




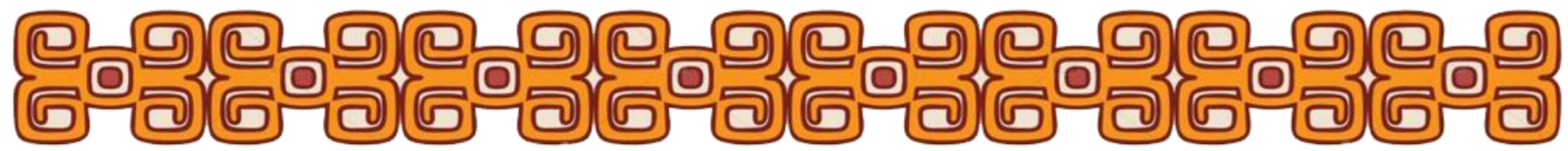

abrangentes sobre o uso adequado dos ambientes naturais de forma sinérgica.

A estrutura simbólica do lugar soma-se a sua própria grandiosidade e historicidades, pois a região é repleto de contos e lendas, que permeiam o imaginário popular, além de ser possível o incremento dos mais variados produtos e serviços turísticos a serem consolidados por meio da parceria público-privadas junto às agências receptivas do turismo almejam em sua atuação o valor sustentável de seu compromisso, firmado a partir dos procedimentos de sua própria existência e devidamente registrada junto ao Ministério do Turismo - MTur ampliam o seu reconhecimento como empreendimento ecologicamente correta, agregando para a sua promoção em nível de captação de potenciais turística, a serem sensibilizados com ações de fomento provenientes da parceria com o Instituto Brasileiro do Turismo - EMBRATUR e em conjunto com a da autarquia federal Instituto Chico Mendes de Conservação da Biodiversidade - ICMBio, e do Instituto Brasileiro do Meio Ambiente e dos Recursos Naturais Renováveis - IBAMA, para o implemento das atividades socioculturais e do turismo em área de unidade de conservação, em conformidade a todas as diretrizes preconizadas nos parâmetros e normas vigentes.

\footnotetext{
"A necessidade de um enfoque de valor sustentável reflete a emergência de um novo ambiente competitivo rico em stakeholders. O crescimento do poder dos stakeholders tem sido motivado pelos aumentos significativos de informações combinados com a elevação das expectativas sociais sobre a saúde e o meio ambiente, provocando uma interface mais estreita entre as empresas e a sociedade civil". (LASZLO, 2008, p. $113-114)$
}

A questão do lugar reúne a atmosfera ideal para a criação de circuitos turísticos como a observação de pássaros em estruturas no contexto do PNV-RR, como torres de observação superficial, e passarelas aéreas que permitam ao contato com a copa das árvores, bem como a "Estrada Perdida", trecho original da BR-174 abandonado pela inviabilidade da obra na região, é o principal acesso terrestre ao interior do Parque. A Estrada Perdida fornece acesso a todo o limite leste da UC, atravessando áreas úmidas de importância especial para a proteção e o turismo no Parque.

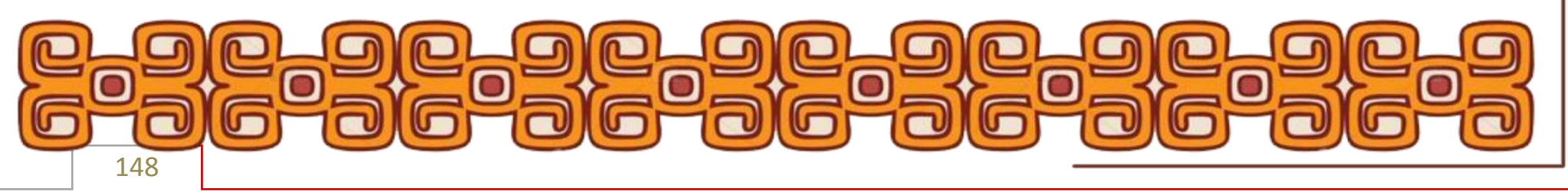




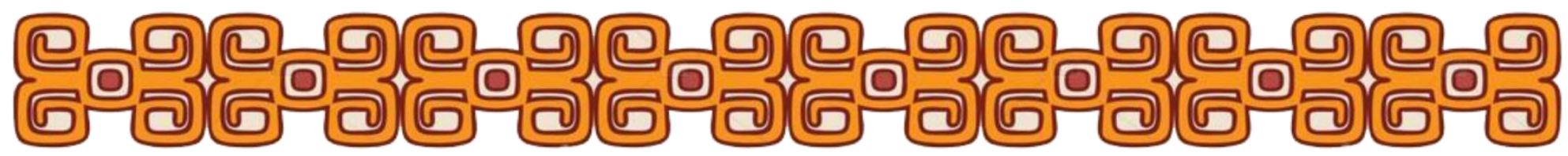

formativas do público de protetores do meio ambiente, os guardiões da Floresta Amazônica, profissionais empenhados na verificação da dinâmica territorial do lugar, assim como indutor da nova forma de interação de consumo.

"[...] manifestação do grande número de cadeias entrelaçadas de interdependência, abrangendo todas as funções sociais que os indivíduos têm que desempenhar, e da pressão competitiva que satura essa rede densamente povoada e que afeta, direta ou indiretamente, cada ato isolado da pessoa". (ELIAS, 1993, p. 207)

A pressão sentida pelos seus integrantes é nítida, pois quanto mais suas complexidades redes e teias configuradas, maior a necessidade de inteligibilidades dos arranjos produtivos incorporados para o pleno exercício de propostas inovadoras, cujas interpretações de interdependências ao grau da pressão interna sentidas pelo indivíduo que dela manterá a vinculação e interação. Os cuidados com o contexto de produção é imprescindivel para garantir a dinâmica de interdependência, pois as reduções dos impactos negativos provenientes de tais povoamentos devem ser os mínimos possíveis para que assim tenhamos resultados ainda mais eficazes desse processo civilizador.

No tocante a própria saúde de cidadãos e cidadãs que buscam promover na sociedade espaços para o entretenimento politicamente correto para o desenvolvimento de atividades saudáveis e cada vez mais aliado ao contexto natural, o que enriquece a qualidade de vida e atribui melhores condições nos índices de desenvolvimento humano para a população local, quanto para os turistas e visitantes que terão a oportunidade de interagir no Parque Nacional do Viruá no Estado de Roraima, como apontam em Norbert Elias.

\footnotetext{
"Seja qual for a relação que esta necessidade possa ter com outras necessidades mais elementares como a fome, a sede e o sexo - todos os dados acentuam o facto de que esta representa um fenómeno muito mais complexo, um fenómeno muito menos puramente biológico -, pode bem considerar-se que o desprezo quanto à atenção dedicada a esta necessidade constitui uma das maiores lacunas na abordagem dos problemas da saúde mental". (ELIAS; DUNNING, 1992, p. 171)
}

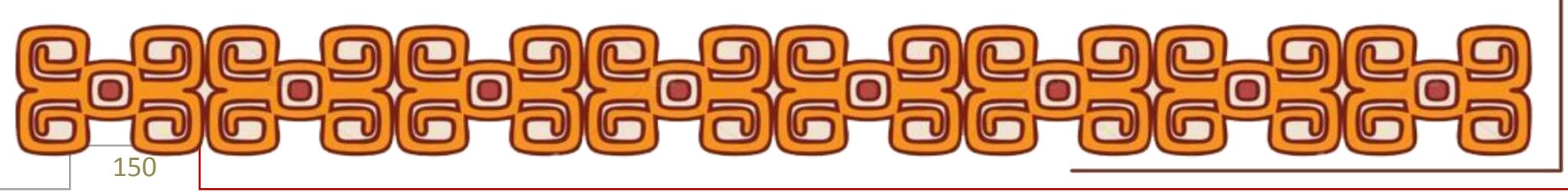




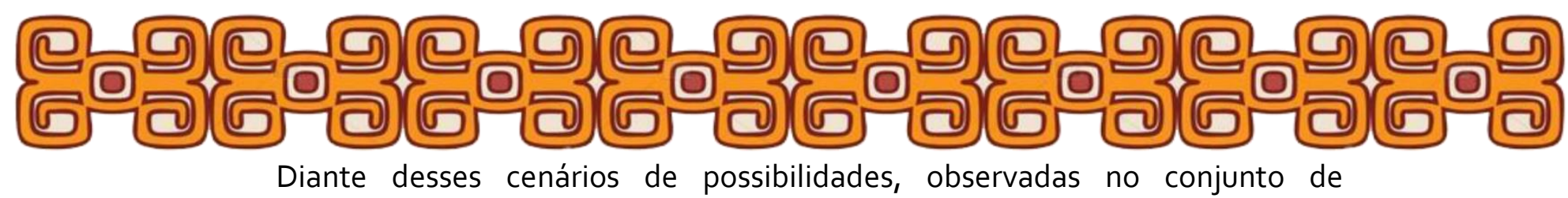

informações e dados disponíveis no Parque Nacional do Viruá, temos a potencial oferta de observação de aves e vida silvestre, caminhadas em trilhas, ciclismo, acampamento em espaço com potencial dos balneários, turismo científico e recreativo, a junção de verdadeiras atividades reunidas em uma programação voltada para a formação educacional com vistas ao aprimoramento do comportamento e postura do turista, visitante e moradores sobre a preservação da Unidade de Conservação Parque Nacional do Viruá em Roraima.

\footnotetext{
"Do período mais remoto da história do Ocidente até os nossos dias, as funções sociais, sob pressão da competição, tornaram-se cada vez mais diferenciadas. Quanto mais diferenciadas elas se tornavam, mais crescia o número de funções e, assim, de pessoas das quais o indivíduo constantemente dependia em todas suas ações, desde as simples e comuns até as complexas e raras. À medida que mais pessoas sintonizavam sua conduta com a de outras, a teia de ações teria que se organizar de forma sempre mais rigorosa e precisa, a fim de cada ação individual desempenhasse uma função social. $O$ indivíduo era compelido a regular a conduta de maneira mais diferenciada, uniforme e estável". (ELIAS, 1993, 2. v, p. 195-196)
}

Os regimes de uso devem seguir aos padrões estabelecidos, assim como a sua institucionalidade garantirá agregar mais valores ao ambiente da Unidade de Conservação pensada para a sua sustentabilidade, e cuja funcionalidade se revigora mediante o firme propósito de cumprimento das normas para utilização de forma equânime do PNV-RR.

Assim a modernização do Parque Nacional do Viruá em Roraima apontam para o implemento de muitas medidas sinérgicas capazes de ampliar a geração de oportunidades, estabelecendo-se com a base de diálogo para as populações viventes em conjunto com a equipe gestora do PNV, comunitários, pesquisadores e consultores contratados para inventários de meio físico, biodiversidade, e capacitação em Gestão para Resultados, com custos cobertos pelo Programa Áreas Protegidas da Amazônia (ARPA), e supervisão pela Coordenação de Elaboração e Revisão de Planos de Manejo do ICMBio, desenvolvem avaliações continuadas capazes de mensurar as várias ramificações e desdobramentos dos projetos a serem incorporados,

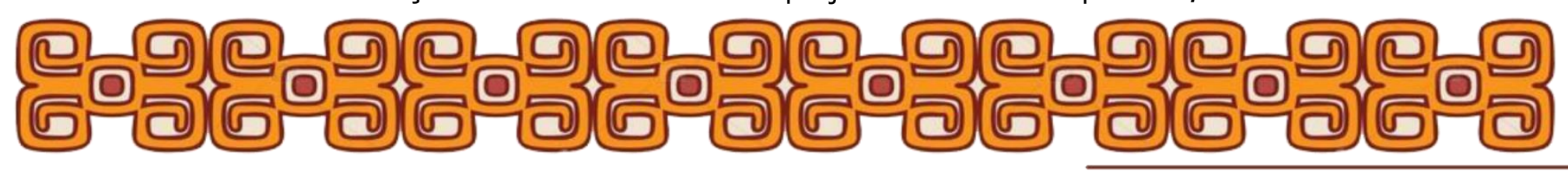




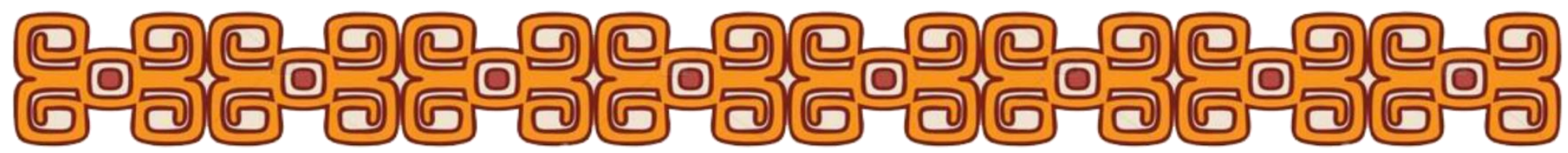

aprimorando e atribuindo novas ressignificações ao conjunto de normas que colocam em redoma a riqueza do ecossistema, além de tornar-se instrumento de total interação entre a sociedade e a natureza nos espaços amazônicos, e fundamental para essas percepções a força de geração de oportunidades justas e rentável no Extremo Norte da Amazônia Brasileira.

"[...] o controle efetuado através de terceiras pessoas é convertido, de vários aspectos, em autocontrole, que as atividades humanas mais animalescas são progressivamente excluídas do palco da vida comunal e investidas de sentimentos de vergonha, que a regulação de toda vida instintiva e afetiva por um firme autocontrole se torna cada vez mais estável, uniforme e generalizada". (ELIAS, 1993, v. 2, p. 193-194).

A estruturação de uma rede estável consolidada em sua base de forma a institucionalizar conduz para novos diálogos nos quais apenas por meio das ações estruturantes de formações de novas configurações para o funcionamento da relação homem-natureza reproduzirão medidas enérgicas, frente ao ecossistema do Parque Nacional do Viruá em Roraima.

\section{CONSIDERAÇÕES FINAIS}

As articulações institucionais fortalecem as novas configurações para o desenvolvimento de socioeconômico e a interação com a natureza, compreendida nesse sentido em Unidade de Conservação do Parque Nacional do Viruá do Estado de Roraima, fortalecendo os diálogos para o aprimoramento da atividade econômica do Turismo Ecológico de Base Comunitária para a inserção dos cidadãos e cidadãs habitantes originários do espaço patrimonial natural e a própria formação da sociedade inserida no contexto da Floresta Amazônica.

As vigências normativas que estruturam a implementação de Unidade de Conservação conduzem para novas perspectivas dialógicas, que viabilizam as novas configurações para a incorporação das ações estruturantes para a viabilidade do turismo ecológico de base comunitária são indutoras da inserção da mão de obra,

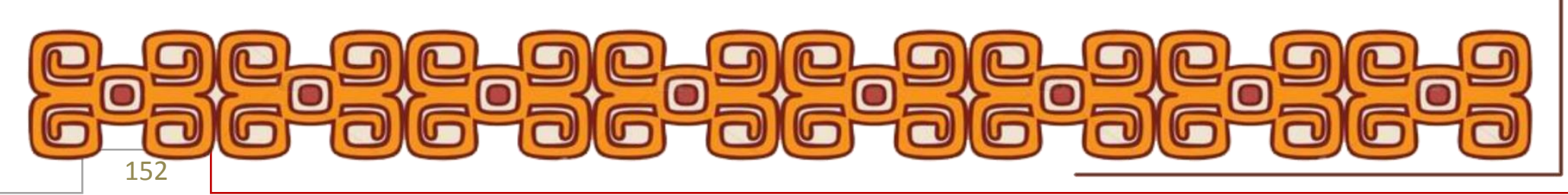




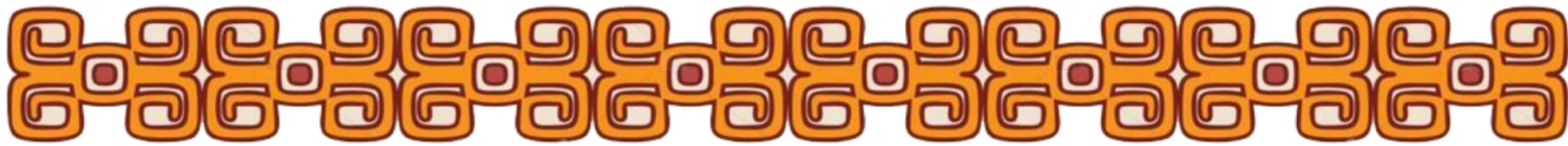

excluída dos espaços urbanos das metrópoles nas quais as próprias condições de formação ao posicionamento do indivíduo são resultantes da precarização do sistema democratizante dos instrumentos de acesso aos recursos.

Nesse sentido, as estruturações de estudos que promovam a história do lugar são fundamentais para o resgate da memória de todo o conjunto espacial em que se inserem historicamente os indivíduos moradores da floresta amazônica nos mais variados contextos de produção, mesclando avanços aos modelos tradicionais e ao próprio reconhecimento de sua presença para o guarnecimento como agentes defensores e protetores da floresta amazônica e toda biodiversidade existe.

Assim, comprovam-se as ferramentas fundamentais para a composição de uma nova lógica de relacionamento sociedade e natureza, na qual a garantia de sua interdependência é essencial para a manutenção inteligível e ao intercâmbio de todas as experiências capazes de promover a condição humana sem impactos negativos, reduzindo-se os desequilíbrios e os avanços da degradação, devastação e biopirataria nos biomas amazônicos, compreendendo o complexo universo de produção e socialização dos saberes e conhecimentos tradicionais.

As leis vigentes seguem parâmetros que não atendem as demandas existentes em toda a sua territorialidade, bem como os organismos de controle sofrem significativamente pelas ineficácias de algumas ações, a fim de inibir a atuação de atores irregulares nos espaços de produção, bem como suas exigências burocráticas inviabilizam a institucionalização de parcerias público-privada, com o propósito de estabelecer a inserção de novos cidadãos e cidadãs.

Há um conjunto histórico a ser resgatado, principalmente as primeiras levas contingenciais que compuseram a formação do povoamento, constituinte pioneiro do ambiente do Parque Nacional do Viruá no Estado de Roraima, que ao longo do rio Iruá, refletiu-se em memórias tanto do lugar, quanto das estruturas que fizeram parte da produção socioeconômica, que não podem ser apagados do conjunto biológico, pois o social é representativo para a formação sociológica e antropológica da Unidade de Conservação Parque Nacional do Viruá em Roraima.

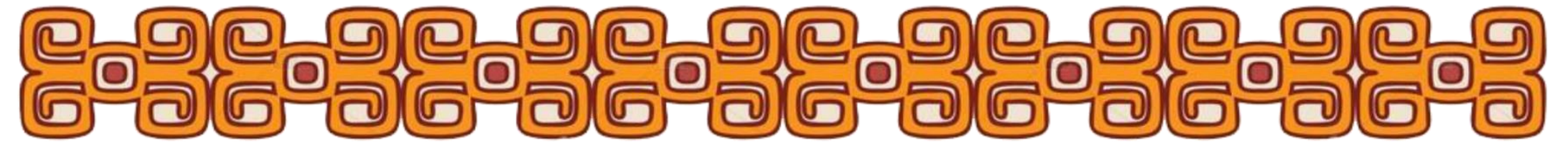




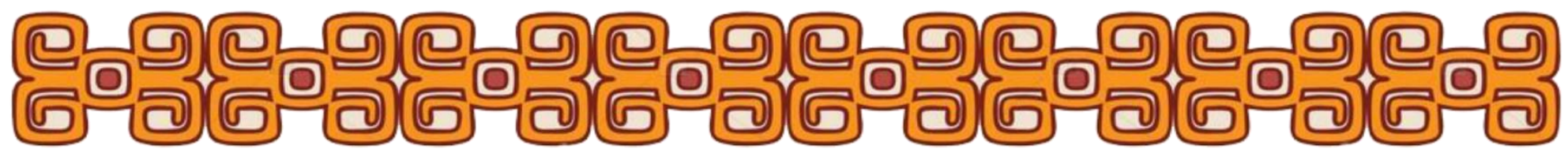

Nessa constante, é extremamente relevante a imediata identificação das características históricas da "Estrada Perdida", na qual a natureza impôs ao homem a sua força, demonstrando que nem sempre os avanços tecnológicos e antrópicos são capazes de invadir a natureza, e que a agressividade imposta de nada adiantaria para a viabilidade econômica, pois se deve coexistir de forma harmônica e interdependente.

\section{REFERÊNCIAS}

BRASIL. ICMBio. Plano de Manejo do Parque Nacional do Viruá. Boa Vista, ICMBio, p.626; 2014 .

ELIAS, Norbert. A Sociedade dos Indivíduos. Rio de Janeiro: Jorge Zahar Editor, $1994 a$.

ELIAS, N., DUNNING, E. A Busca da Excitação. Tradução Maria Manuela Almeida e Silva. Lisboa:

DIFEL, 1992.

. O Processo Civilizador, 2 vols. Rio de Janeiro: Jorge Zahar Editor, $1994 b$.

. O processo civilizador: uma história dos costumes. Tradução Ruy Jungmann. Rio de Janeiro: Jorge Zahar, 1994. 1 V.

O processo civilizador: formação do estado e civilização. Tradução Ruy Jungmann. Rio de Janeiro: Jorge Zahar, 1994. 2 v.

LASZLO, Christopher. Valor sustentável: como as empresas mais expressivas do mundo estão obtendo bons resultados pelo empenho em iniciativas de cunho social/ Chris Laszlo; [tradução Celso Roberto Paschoa]. - Rio de Janeiro: Qualitymark, 2008.

MATOS, GLÁUCIO, C, G. Ethos e Figurações na Hinterlândia Amazônica. Manaus: Valer/Fapeam, 2015.

MOREIRA, Eliane. Conhecimento tradicional e a proteção. T\&C Amazônia, ano V, n. 11, jun. 2007. Revista eletrônica Disponível em: <http://tecamazonia.com.br/wpcontent/uploads/2017/03/revista_tec_ed11.pdf>; Acesso em: 08.08.2018, às 21h39min. RIVAS, Alexandre. Economia e valorização de serviços ambientais utilizando técnicas de preferências declaradas. / Alexandre Rivas. - Manaus: EDUA, 2014.

RODRIGUES, Débora Cristina Bandeira. Conhecimentos tradicionais e mecanismos de proteção: estudo de caso nas comunidades de Ebenézer e Mucajá em Maués/ AM. - Manaus: Edua, 2015.

TEIXEIRA, Pery. Produzir e viver na Amazônia rural: estudo sociodemográfico de comunidades do Médio Solimões. / organizadores, Pery Teixeira, Marília Brasil, Alexandre Almir Ferreira Rivas, Renata R. Mourão. - 2. Ed. rev. - Manaus: Reggo Edições, 2011.

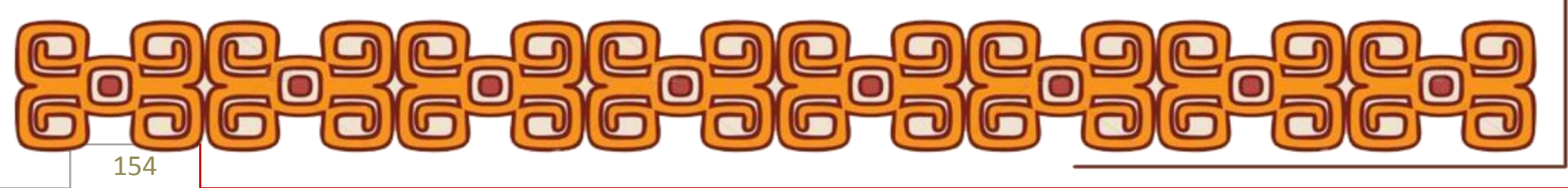




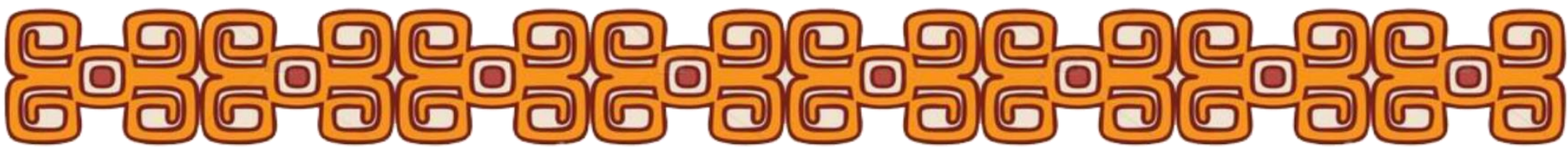

VIANA, Virgílio Maurício. Manejo florestal sustentável para a produção de madeira no Estado do Amazonas./ organizadores, Virgílio Maurício Viana, Marelete Siqueira Tupinambá; Ozenete Aguiar De Mozzi; Phillippe "Tim" Waldhoff - Manaus: Edições Governo do Estado do Amazonas/ secretaria de Estado de Meio Ambiente e Desenvolvimento Sustentável/ Secretaria de Estado da Educação e Qualidade do Ensino./ Comissão Interinstitucional de Educação Ambiental, 2008. (Série Amazonas Sustentável).

$V A L$, Adalberto Luís. Bases científicas para estratégias de preservação e desenvolvimento da Amazônia: fatos e perspectivas. Editado por Adalberto Luís Val; Roberto Figivolo e Eliana Feldberg. Manaus, 1991.

VILA NOVA, Sebastião. Introdução à sociologia - 6. Ed. rev. e aum. - São Paulo: Atlas, 2004.

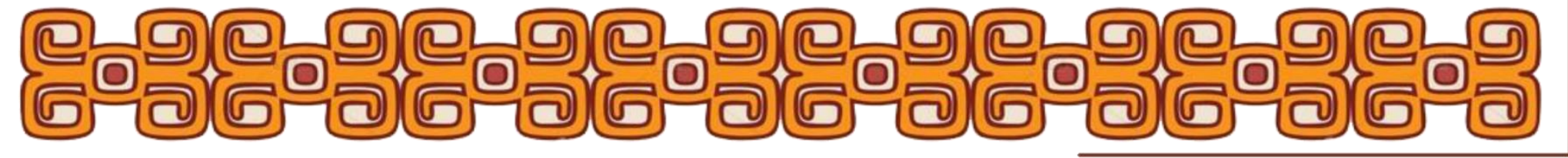

